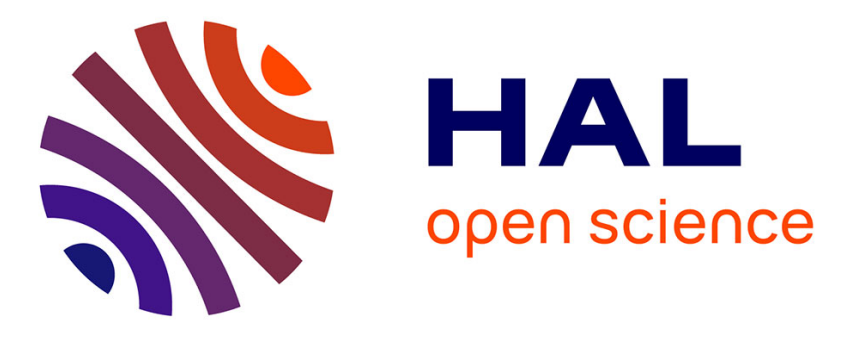

\title{
Exploring Late Pleistocene climate variations
}

\author{
M. Sarnthein, J. Kennett, J. Chappell, T. Crowley, W. Curry, J.C. Duplessy, \\ P. Grootes, I. Hendy, C. Laj, J. Negendank, et al.
}

\section{To cite this version:}

M. Sarnthein, J. Kennett, J. Chappell, T. Crowley, W. Curry, et al.. Exploring Late Pleistocene climate variations. Eos, Transactions American Geophysical Union, 2000, 81 (51), pp.625. 10.1029/EO081i051p00625-01 . hal-03245041

\section{HAL Id: hal-03245041 \\ https://hal.science/hal-03245041}

Submitted on 2 Jun 2021

HAL is a multi-disciplinary open access archive for the deposit and dissemination of scientific research documents, whether they are published or not. The documents may come from teaching and research institutions in France or abroad, or from public or private research centers.
L'archive ouverte pluridisciplinaire HAL, est destinée au dépôt et à la diffusion de documents scientifiques de niveau recherche, publiés ou non, émanant des établissements d'enseignement et de recherche français ou étrangers, des laboratoires publics ou privés.

$$
\text { Copyright }
$$


Eos, Vol. 81, No. 51, December 19, 2000
$\mathrm{E} \mathrm{OS}$,
T R A N S A C T I O N S,
A M E R I C A N
GE O PH Y S C A L
U N I O N

EOS

VOLUME 81 NUMBER 51

DECEMBER 19, 2000

PAGES 625-640

\section{Exploring Late Pleistocene Climate Variations}

\section{PAGES $625,629-630$}

The origin of much of the variability in late Quaternary climate remains a major question in the understanding of processes of past and future climate change. The origin of major rapid, decadal climate change during the latest Quaternary remains an enigma. These issues are critical for understanding global change. Although major progress continues to be made, a general consensus has developed that limitations in knowledge of the chronology of millennial-scale climate variability are impeding further progress.

However, a suite of valuable techniques, approaches, and potential new site locations can improve our understanding of the chronology of rapid climate change. The idea of creating a joint global time scale of decadal-to-millennialscale climate oscillations was discussed by more than 50 scientists from various disciplines at the SCOR-IMAGES (Scientific Commission of Ocean Research-The International Marine Past Global Change Study) Workshop in Trins, Austria, February 16-19,2000. Their recommendations are reported at the end of this article.

\section{New Millennial-Scale Climate Variability}

The Late Quaternary climate was highly unstable and prone to large, rapid changes that could be as short as a few decades. Curiously, this instability was particularly pronounced during the last ice age, when ice sheets covered northern high-latitude continents, which led to exposure of the continental shelves. First identified in ice cores drilled through the Greenland ice sheet, a series of warm phases called Dansgaard/Oeschger (DO) interstadials punctuate the otherwise cold conditions of the last glacial [Hammer et al., 1997] between $\sim 20$ and 80 k.y.a. These climate oscillations essentially reflect a switching of the ocean-atmosphere system between two principal modes, warm and cold, indicating bistable behavior. Even more remarkable is the speed of these transitions; they range from decades to just a few years, as first identified in Greenland ice cores [Hammer et al., 1987 and references therein].

Since these first discoveries from the Greenland Summit cores in the early 1990s, the record of this unexpected climatic behavior has been found in many regions (Figure 1), including polar ice sheets; marine sediments of the Atlantic, Pacific, and Indian Oceans; and in terrestrial lakes and bogs. DO cycles are recorded, for example, by changes in oxygen isotopes $\left(\delta^{18} \mathrm{O}\right)$ of polar ice; in sea surface temperatures and $\delta^{18} \mathrm{O}$ of sea water recorded in foraminiferal shells in marine sediments; and in climate curves of pollen assemblages from lake sediments (Figure 2).These climate fluctuations are also recorded by significant oscillations in atmospheric trace gases (such as $\mathrm{CH}_{4}$ ) in the ice cores and in large changes in the marine and terrestrial biosphere. Clearly, much recent evidence suggests that the Earth system as a whole experienced this unstable behavior during the last glacial cycle.

The origin of this climatic behavior largely remains a mystery, although certain associations have emerged that clearly are critical in the assessment of processes that drive the
Earth's system in this manner. For example, there is mounting evidence that changes in the system were associated with abrupt switches in the strength of the North Atlantic thermohaline circulation and "The Great Ocean Conveyor" [van Kreveldet al., 2000, and references therein]. Recent evidence has emerged that perhaps even the source of oceanic shallow intermediate waters has likewise oscillated in close concert with these climate changes [Kennett et al.,2000]. Distinctive patterns have emerged. There appears to be a vague $\sim 7200$-year oscillation, with each episode consisting of several DO cycles [Bond et al., 1993, cited in van Kreveld et al., 2000], where both the first warm interstadial and the last cold stadial were of longest duration. The cycle climaxes with a severely cold Heinrich event.A saw-tooth pattern of change at the millennial scale is evident in certain records, much like the well-known saw-tooth pattern at the Milankovitch or orbital time scale that is expressed, for example, in the 100 k.y. cycle that marks the late Quaternary.

Much has been accomplished toward understanding the extent and magnitude of this behavior in the Earth's system. However, further progress requires studies of climatic

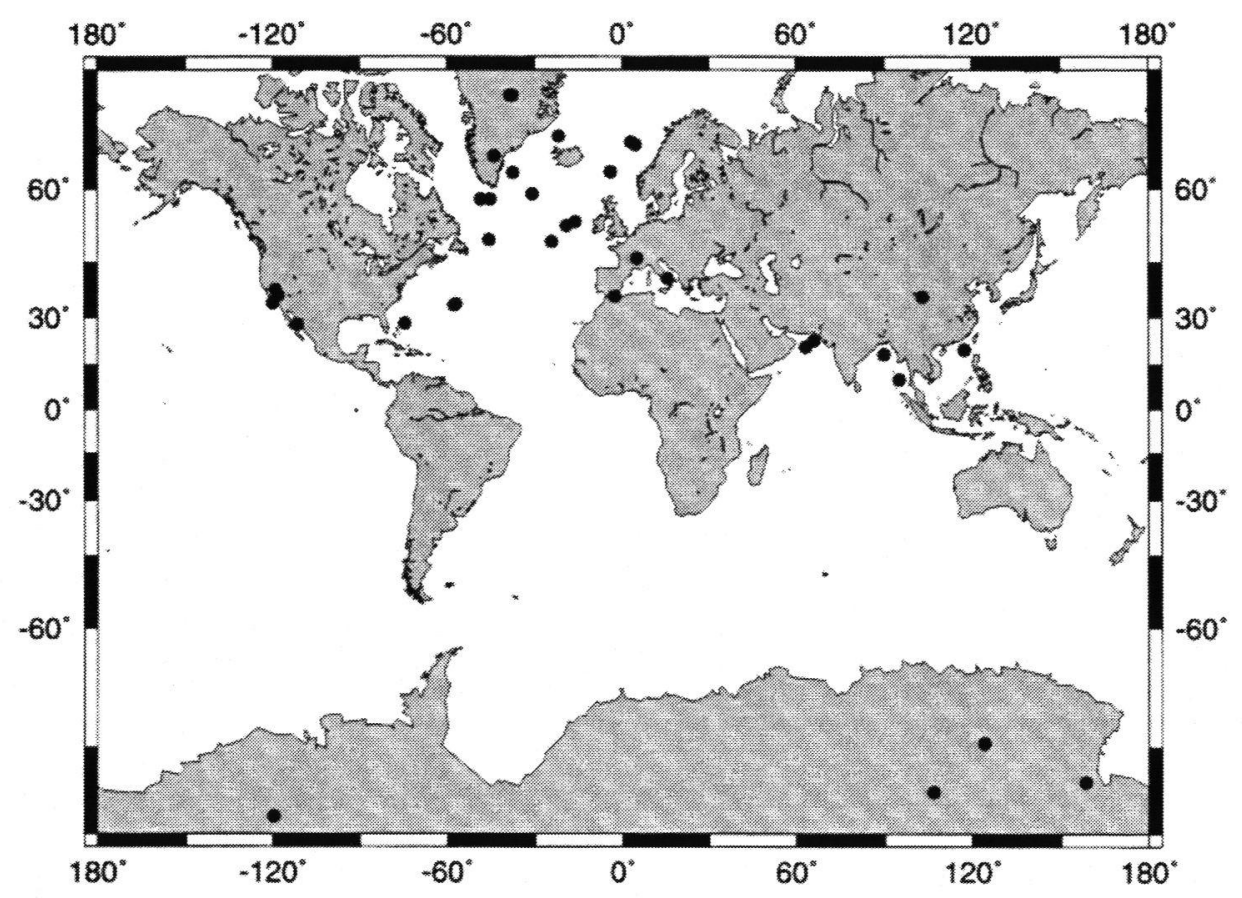

Fig. 1. Global distribution of sites with paleoclimatic records of the last 40-80 k.y. with a resolution better than 100-200 years. 


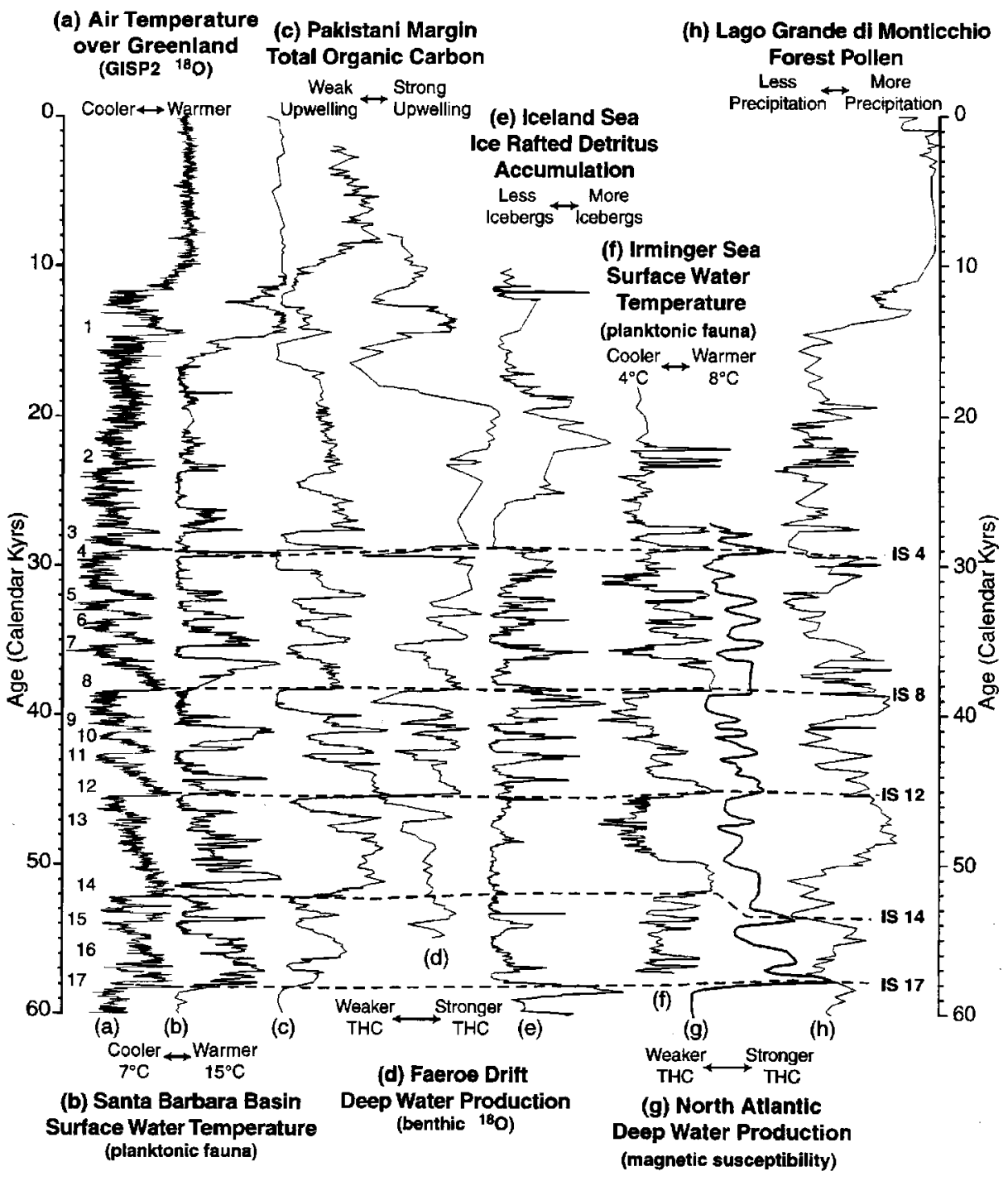

Fig. 2. Global comparison of high-resolution, rapid climate change records. From left to right: (a) $\delta^{18} \mathrm{O}$ record from the GISP2 ice core [see Stuiver and Grootes in Hammer et al., 1997]; (b) $N$. pachyderma dextral to sinistral coiling ratio from ODP Hole 893A, Santa Barbara Basin [Hendy and Kennett, 2000 J;(c) total organic carbon record from core SO90-136KL, Pakistani Margin [Schulz et al., 1998]; (d) benthic $\delta^{18} O$ record of Faeroe Drift deposits [Rasmussen et al., 1996]; (e) ice-rafted detritus accumulation for core PS2644, Western Iceland Sea [see Voelker in van Kreveld et al., 2000]; (f) sea surface temperature based on faunal assemblages for core SO82-5, Irminger Sea [van Kreveld et al., 2000]; (g) magnetic susceptibility for core MD95-2010, Norwegian Sea [see Kissel et al., 1999, cited in Laj et al., 2000]; and (h) woody taxa pollen abundance for Largo Grande di Monticchio [Allen et al., in Zolitschka, 1999].

records at very high decadal resolution, because the extremely rapid changes in the Earth system have global responses, some of which appear synchroneous when transmitted through the atmosphere, and others sometimes appear diachroneous when transmitted through the ocean. Climate changes appear synchroneous between Greenland, California margin waters, and the Cariaco Basin (tropical Venezuela), and anti-phased between the north and south Atlantic basins, and between Greenland and parts of Antarctica.

Poor understanding of temporal relations between climate changes around the Earth hinders understanding of the processes that caused past climatic instability and rapid climate change. Since climatic feedback mechanisms must have played a central role in creating abrupt change over only a few decades, it is crucial to understand and date leads and lags between different global environmental systems. This requires the development of high-resolution stratigraphic records for the late Quaternary with accurate calendar year chronologies. Creation of a global time scale of decadal-to-millennial-scale climate oscillations has become a pressing issue.

Significant progress can be gained by establishing calendar year chronologies in terrestrial and marine records for the last $80 \mathrm{k.y}$., testing hypotheses for late Quaternary climate behavior by acquiring critical new records, and analyzing new and existing records using multiple approaches at higher temporal resolution.

\section{Calendar Year Chronologies for the Last $80 \mathrm{k.y}$.}

Techniques that can be employed to help establish calendar year chronologies for stratigraphic records representing the last $80 \mathrm{k.y}$. fall into three categories: incremental dating, radiometric dating, and correlation/ matching procedures

Incremental dating techniques provide continuous and independent calendar year chronologies. Dendrochronology - annual rings laid down by long-lived trees in temperate regions of the world-provides one of the best annual records. Ring-width variations can be cross-matched between trees and a composite calendar year time scale can be constructed. A continuous dendrochronology now extends to 11,800 calendar years B.P. Older "floating" sections of dendrochronologjcal records have yet to be tied to the continuous record; once this is achieved, a detailed calibration curve will extend to $\sim 40$ k.y. B.P. However, it is rarely possible to apply dendrochronological dates to other records without cross-matching between tree ring measurements and other proxies.

Ice cores from polar ice sheets yield extremely valuable paleoclimatic archives. Major strengths of these records are their very high stratigraphic resolution (sub-annual in upper parts) and the many paleoenvironmental proxies represented. Changes in many of these proxies can be directly compared with each other with no phase uncertainty, although critical uncertainties exist in the transfer of well-established ice time scales to atmospheric gas records. The stratigraphically best-resolved records for the last climate cycle have been derived from two cores drilled at the summit of Greenland. The Greenland Ice Sheet Project 2 (GISP2) and Greenland Ice Core Program (GRIP) data sets were published simultaneously [Hammer et al., 1997]. However, several different time scales now exist for each ice core and an integrated optimal time scale has yet to be established using both cores.

The GISP2 time scale was derived by continuous counting of several properties exhibiting a seasonal cycle; conservatively estimated errors range from $2 \%$ over the last 40 k.y. to about $20 \%$ at 110 k.y. B.P. Older than about 50 k.y. B.P., the widely used GISP2 time scale uses a comparison of $\delta^{18} \mathrm{O}$ of oxygen in trapped air with that in the Vostok, record and is consistent with the marine SPECMAP project time scale. This provides a time scale with probably somewhat smaller uncertainties at 100 k.y. B.P.

The GRIP time scale back to -7 k.y.a. is based on correlation with the counted Dye-3 record using volcanic acidity layers as data. Continuous layer counting in GRIP was used between 7 k.y. B.P. and the Oldest Dryas/ Bolling transition at $\sim 14.5$ k.y.a. Ice flow modeling, incorporating smoothly varying accumulation estimates based on the $\delta^{18} \mathrm{O}$ record, and using age control points at the Younger Dryas/Pre-boreal transition (11.5 k.y. ago), and MIS $5 \mathrm{~d}$ (110 k.y.ago), was used to construct the remainder of the GRIP "ss08 
time scale."An independent time scale for GRIP back to -60 k.y. B.P. is based on counts of annual dust layers [Hammer et al., 1997]

Annual laminations or varves can be preserved in both marine and lacustrine sediments. Marine varved chronologies usually only represent fragments of the last 80 k.y. (for example, 9-15 k.y.ago) in the Cariaco Basin [Hughen et al., 1998]. Lacustrine environments [Zolitschka, 1999] can provide ideal conditions for the development of varved sediment sequences for the length of the life of the lake. Examples include Lake Gosciaz in Poland, Lake Holzmaar and Meerfelder Maar in Germany, Lake Monticchio in Italy, Elk Lake in the United States, and possibly Lake Suigetsu in Japan; but none completely covers the last glacial cycle.

Corals and speleothems may exhibit annual growth bands, thus providing a calendar year chronology. However, these records are usually limited to the last few centuries. Fossil corals can provide records representing older time windows. These provide "floating" chronologies that require dating using other approaches such as ${ }^{14} \mathrm{C}$ and U-series dating. Speleothem dating is often limited by progressive fading of the growth bands, which thus tend to lose their annual resolution.

\section{Comparing Incremental Dating Techniques}

The time scales developed for the Greenland ice cores have special value extending far beyond that of ice core studies for several reasons. They certainly provide the longest archives for studies of features such as the 11-year sunspot cycle. Some hypotheses for explaining climatic variability rely on timeseries analyses, which are critically dependent on the integrity of the time scale. Paleoceanographic records can only obtain a precise time scale sufficient for time-series analysis by correlation with the Greenland ice core record. Correlation to Greenland obviously provides an essential link for ensuring accuracy of Antarctic ice core chronologies. The accuracy of time scales based on annual layer counting in lake sediments and tree rings can ultimately be checked only by comparison with other annually resolved time scales. The Greenland records should remain an ultimate means for such checking. Increasingly important paleoclimatic time series are based on "floating" annually resolved time scales. These include stalagmite sections, pieces of wood, and lake sediment records that do not extend to the present. Their value is enhanced when they are calibrated with the continuous Greenland ice core time scale

\section{Radiometric Techniques}

Radiometric techniques provide discrete dates and continuous chronology UraniumThorium $\left.{ }^{230} \mathrm{U} /{ }^{234} \mathrm{Th}\right)$ dating using thermal-ionization mass spectrometry (TIMS) can be used to date materials from speleothems, corals, carbonate deposits, peat, and bones from 350 to 5 k.y.a. The crucial prerequisite for this technique is that there has been no loss or gain of nuclides since deposition; that is, the system must be closed. Unlike ${ }^{14} \mathrm{C}$, the formation of these nuclides does not depend on variations in solar activity or reorganizations in the global carbon cycle. When correcting for various sources of error, such as inherited Th, this technique provides calendar year chronologies.

Radiocarbon dating is widely used for dating materials up to $\sim 50$ k.y. B.P. Carbon 14 dating by decay counting or accelerator mass spectrometry (AMS) has an age uncertainty ranging from about $+20-30$ years for samples back to 10.5 k.y. ago, up to \pm 100 years back to $20 \mathrm{k} . \mathrm{y}$ ago, and up to $> \pm 1000$ years forages close to the limits of counting statistics depending on the age and size of a sample. Radiocarbon ages require calibration because the atmospheric ${ }^{14} \mathrm{C} /{ }^{12} \mathrm{C}$ ratio was not constant in the past due to changes in the ${ }^{14} \mathrm{C}$ production rate and the oceanic carbon system. Calibration is necessary for comparing ${ }^{14} \mathrm{C}$ dated records to other calendar year records, and this increases error. The problem is exacerbated by plateaux in the calibration curves resulting from large temporal variations in atmospheric ${ }^{14} \mathrm{C}$ content. Back to 11.8 k.y. B.P. the calibration use ${ }^{14} \mathrm{C}$ dating of dendrochronologically dated tree rings. This will be extended into the late glacial episode when floating dendrochronologies of this age are tied to the Holocene master record. Beyond these limits back to about 55 k.y. B.P., attempts to extend the calibration curve are based on: ${ }^{23} \mathrm{U}^{234} \mathrm{Th}$ ages of corals; annually laminated sediments from marine [Hughen et al., 1998] and lacustrine sediment sequences; and indirect calibration by measuring at high resolution the ${ }^{14} \mathrm{C}$ ages on well established climatic time series, thus allowing detailed crossmatching with well-dated climate records; for example, Greenland ice cores [van Kreveld et $a l ., 2000$ and references contained therein]. In addition, dates of marine sediments may be affected by the local ${ }^{14} \mathrm{C}$ reservoir of the ocean. This local effect may vary by the same magnitude as potential leads and lags between various climate signals of DO cycles and thus add uncertainties to the interpretation of marine paleoenvironmental records.

To overcome these calibration problems, ${ }^{14} \mathrm{C}$ ages must be measured at high resolution in mo:e annually laminated records that have independent calendar-year chronologies and finally, to assemble a single ${ }^{14} \mathrm{C}$ calibration curve from these records for the past 50 k.y.

\section{Correlation Techniques}

Certain correlation techniques enable synchronous cross-matching of proxies for transfer of chronology from a dated to an undated climate record.

Geomagnetic paleo-intensity is a synchronous signal that is employed for global correlation of many geological records. Geomagnetic excursions and events are used as master tie points between separate records. An example is the new high-resolution paleo-intensity record from North Atlantic marine sediments
(NAPIS-75) of late Quaternary age (75-10 k.y. B.P; Laj et al., 2000). The stacked record has been dated by correlation of one of the cores to the GISP2 ice core via $\delta^{18} \mathrm{O}$ meltwater signals [van Kreveld et al.,2000]. Refined techniques are necessary for precise and objective correlations using the entire character of the paleointensity records. This should soon enable global correlations with an uncertainty of less than $2-5$ k.y.

Volcanic ash layers, when described in terms of their geochemical and mineralogical properties, can also be utilized as event markers (datums) to correlate ice and sediment cores. Furthermore, such events are suitable for ${ }^{3} \mathrm{Ar} /{ }^{40} \mathrm{Ar}$ dating with an error of $2 \mathrm{k}$.y. or less for the last $80 \mathrm{k.y}$.

Changes of sea level directly express changes in the volume of continental ice sheets. Such changes can be determined from study of coral reef deposits dated by ${ }^{14} \mathrm{C}$ or ${ }^{230} \mathrm{U} /{ }^{234} \mathrm{Th}$ methods. Coral terraces at sites with high tectonic uplift provide detailed records of past sea level changes. However, the use of sea level stands as global chronological markers are often problematic because of the complicating effects of local tectonics, storms, and tsunamis.

\section{Testing Explanations for Millennial- Scale Climate Variability}

Many records of varying chronological resolution now exist that clearly exhibit rapid oscillatory behavior in climate at centennialthrough-millennial time scales, much like the DO cycles recorded in the Greenland ice. Examples of some particularly high-resolution time series are shown in Figure 2.These records describe variability in the atmosphere-ocean system through proxies reflecting changes; for example, in polar and sea surface temperature. Several hypotheses have been proposed [van Kreveld et al., 2000] to explain such phenomena, at least in part. The most prominent is variations of the Global Conveyor and lowfrequency variability in the eastern equatorial Pacific upwelling system. Different mechanisms may have triggered such variability. Variability in conveyor strength may have been produced by meltwater pulses in the northern North Atlantic linked to internal ice sheet instabilities, by variations in surface water circulation in the tropical Atlantic, or by changes in solar irradiance. In the equatorial Pacific, circulation changes might represent a resonant time scale for the Pacific Basin as a whole, and thus climate change of global magnitude. The two mechanisms may be interdependent, with variations in equatorial Pacific climate affecting the North American and Greenland ice sheets and, in turn, conveyor circulation. Conversely, changes in the conveyor may trigger trade wind changes in the eastern equatorial Pacific, or changes in the strength of the Siberian high may influence westerly wind bursts in the western equatorial Pacific or changes in upwelling of cold deepwater in the northwestern-most Pacific.

Each mechanism above has a different "fingerprint" in the time and space domains. Thus, 
regions on land and in the ocean that appear to have played a key role in rapid, millennialscale climate variability need to be targeted for future high-resolution climate studies to test different mechanisms of climate change. Nevertheless, because understanding of such processes is at an early stage, a delicate balance needs to be struck between targeted sites and those of serendipity. "Incomplete" high-resolution records of climate change, including varved sequences and speleothems, should also be targeted for the last 80,000 years, since this information is often valuable

\section{Recommendations of SCOR-IMAGES Workshop}

Participants reached a consensus about many recommendations. First, a significant coordinated effort should be made to develop a new calendar time scale for the Greenland GISP2 and GRIP ice core records. This highly detailed record should be upgraded as new information becomes available.

Joint research efforts should be initiated across various disciplines to improve the global time scale of millennial climate oscillations. This should establish a common ${ }^{14} \mathrm{C}$-time scale based on existing annually laminated sediment and ice records and to locate additional laminated lacustrine and marine records, calibrate the common ${ }^{14} \mathrm{C}$-time scale back to 55 k.y. B.P., define variations in the ${ }^{14} \mathrm{C}$ reservoir effect in various ocean basins, validate and promote the geomagnetic palaeo-intensity record as a dating tool, and establish a set of global time markers.

New records should be obtained to test various components of the conveyor hypothesis. These include north and tropical Atlantic cores to examine phase relations between deep-and surface-water hydrography and their origin, icerafting events, meltwater and brine pulses, and indications of tropical humidity changes; south Atlantic sites where the Atlantic seesaw would predict increased sea surface temperatures and southem African precipitation during DO stadials; and regions affected by meltwaterinduced changes in the strength of the Siberian high and its effect on the south and east Asian monsoons. Such sites would be useful in testing whether sub-polar north Pacific sea surface temperature is controlled by coeval atmospheric forcing or rather by thermocline ventilation at the terminus of the "global conveyor" in anti-phase with north Atlantic changes.

New records should also be obtained in the high latitudes of the Southern Ocean and Antarctica.These might record anti-phase behavior between the Northern and Southern Hemispheres. Since the conveyor also predicts a westeast seesaw in Antarctic Circumpolar flow, cooling in the Ross Sea may be in-phase with North Atlantic cooling.
Obtaining new sequences in the equatorial Pacific would provide records of: warming episodes in the eastern equatorial Pacific; aridity in Australia (as detectable using pollen records); sea-surface temperature increases along the west coast of North America; precipitation in the American southwest; upwelling along the Peru/Chile margin; and potential climatic links with central Canada

Studies of the potential role of low-frequency solar irradiance changes in millennial-scale climate variability would also be valuable. Studies of Holocene records provide some support for the role of low-frequency solar irradiance changes in contributing to decadal-tomillennial-scale climate variability. If so, such variability may also be detected in ice age records. Better testing of the solar hypothesis requires the production of more ${ }^{10} \mathrm{Be}$ and ${ }^{36} \mathrm{Cl}$ data to assist with the separation of the cosmogenic effect from the ${ }^{14} \mathrm{C}$ record, the latter of which is also influenced by changes in thermohaline circulation.

High-resolution records of continental climate change need to be developed with improved age control, particularly in the Southern Hemisphere. Models suggest that the solar signal is stronger over land, with the same sign of response in both hemispheres. New and existing records should be analyzed to test mechanisms of climate change. A number of complementary and overlapping approaches may lead to better understanding of centennial/millennial-scale climatic change, two of which are "zereo'th order" best-fit correlations between different time series and the standard Greenland ice core records. Time slice studies of selected DO oscillations should document the spatial evolution of oceanic and atmospheric patterns. Other pressing research needs include the effect of millennial-scale climate changes on methane and carbon dioxide variations of the atmosphere and potential feedbacks of atmospheric trace gas changes on centennial-to-millennial-scale oscillations; intensive statistical examination of the 1500-year cycle to determine its robustness, bandwidth, and coherence and phase relationships between different regions; and an examination of periodicities of the DO band other than the 1500-year cycle.

Centennial/millennial-scale fluctuations in non-glacial sections also deserve analysis. Even though such oscillations are of lower amplitude than their glacial cousins [Martinson et al., 1995], the removal of the greatly complicating effect of most of the Northern Hemisphere ice sheets may enable isolation of the relative importance of other sources of forcing, especially during the last 1000 years, where time and space control of samples is very good. Finally, intercomparisons of climate models will allow assessment of the robustness of model-predicted responses to various episodes, including meltwater pulses and equatorial Pacific climatic oscillations.

\section{Acknowledgments}

The Trins Workshop was supported by SCOR, IMAGES, Volkswagen, and the U.S National Science Foundation. This article was prepared by members of the Trins workshop.

\section{Authors}

M. Sarnthein, J. P.Kennett, J. Chappell, T. Crowley, W. Curry, J. C. Duplessy, P. Grootes, I. Hendy, C. Laj, J. Negendank, M. Schulz, N. J. Shackleton, A. Voelker, B. Zolitschka and the other Trins workshop participants

For additional information, contact M. Sarnthein, Institut für Geowissenschaften, University of Kiel, D-24098 Kiel, Germany;

E-mail:ms@gpi.uni-kiel.de

\section{References}

Eos'limitation on the numbers of references precludes a balanced listing of all relevant publications

Hammer, C., PA. Mayewski, D. Peel, and M.Stuiver (eds.), Greenland summit ice cores,J. Geophys. Res., 102, C12, 1997.

Hendy, I. L and J. P.Kennett, Dansgaard-Oeschger cycles and the California Current System:Planktonic foraminiferal response to rapid climate change in Santa Barbara Basin, Ocean Drilling Program hole 893A, Paleoceanogr, 15,30-42,2000.

Hughen, K.A., J.T.Overpeck, S. J.Lehman, M. Kashgarian, J.Southon, R.Alley, and D.M.Sigman, Deglacial changes in ocean circulation from an extended radiocarbon calibration, Nature, 39/,65-68, 1998 Kennett, J. P., K. G. Cannariato, I. L. Hendy, and R. J. Behl, Carbon isotopic evidence for methane hydrate instability during Quatemary interstadials, Science, 288 $128-133,2000$

Laj, C., C. Kissel,A. Mazaud, J. E.T.Channell, and J. Beer, North Atlantic paleointensity stack since 75 k.a. (NAPIS-75) and the duration of the Laschamp event, Phil.Trans. R.Soc. London A, 358, 1009-1025, 2000.

Martinson, D.G., et al., Natural Climate Variability on Decade-to-Century Time Scales, 630 pp., National Academy Press, Washington, D.C., 1995.

Rasmussen, T. L., E. Thomsen, L. Labeyrie, and T. C. E van Weering, Circulation changes in the FaeroeShetland Channel correlating with cold events during the last glacial period (58-10 k.a.), Geology, 24,937-940, 1996

Schulz, H.,U.von Rad, and H.Erlenkeuser, Correlation between Arabian Sea and Greenland climate oscillations of the past 110,000 years, Nature, 393,54-57, 1998.

van Kreveld,S., M.Sarnthein, H. Erienkeuser,PGrootes, S. Jung, M.J. Nadeau, U. Pflaumann, and A.Voelker, Potential links between surging ice sheets, circulation changes, and the Dansgaard-Oeschger cycles in the Irminger Sea, 60-18 kyr, Paleoceanogr., 15, 425-442, 2000

Zolitschka, B., (ed.), High-resolution records from European Lakes, Quat. Sci. Rev., 18, 7, 1999. 